\title{
Nanostructured Ti-Ni Shape Memory Alloys Produced by Thermomechanical Processing
}

\author{
S. Prokoshkin ${ }^{1} \cdot$ V. Brailovski ${ }^{2} \cdot$ K. Inaekyan ${ }^{2}$. \\ V. Demers ${ }^{2} \cdot$ A. Kreitcberg ${ }^{2}$
}

Published online: 9 July 2015

(C) ASM International 2015

\begin{abstract}
This article describes the evolution of structural and functional properties of Ti-Ni SMA as a result of thermomechanical processing combining cold/warm deformation ranging from moderate to severe and postdeformation annealing at different temperatures. This study results in the development of an original thermomechanical processing route capable of producing truly nanocrystalline Ti-Ni SMA with grain size ranging from 40 to $80 \mathrm{~nm}$. These structures are mainly a result of crystallization at moderate temperatures of the alloys subjected to severe "amorphizing" cold rolling. A clear demonstration is made that the nanocrystalline structures are the most favorable structures, compared to their recrystallized and polygonized counterparts, for the practical application of $\mathrm{Ti}-\mathrm{Ni}$ alloys from the viewpoint of their static and dynamic functional characteristics. Despite the fact that these results were obtained on relatively small-sized samples $(0.2 \ldots 0.7 \mathrm{~mm}$ thick, $3 \ldots 5 \mathrm{~mm}$ wide cold/warm-rolled ribbons), they bring a clear understanding of the underlying processing-structure-properties interrelations, and, therefore, pave the way for the oncoming production of largesize nanocrystalline $\mathrm{Ti}-\mathrm{Ni}$ SMA with a radically improved combination of functional characteristics.
\end{abstract}

Keywords Ti-Ni shape memory alloys $\cdot$ Nanostructures . Thermomechanical processing . Functional properties

S. Prokoshkin

prokoshkin@tmo.misis.ru

1 National University of Science and Technology "MISIS", 4 Leninskiy Prospect, Moscow 119049, Russia

2 Ecole de Technologie Supérieure, 1100, Notre-Dame Street West, Montreal, QC H3C 1K3, Canada

\section{Introduction}

Ti-Ni-based shape memory alloys (SMA) are among the most important functional materials extensively used in medical and other special-purpose technical fields [1-6], and, therefore, the control and the improvement of their functional properties are of continuing interest.

The main functional properties of SMA are highly structure-sensitive and can be listed as follows: recovery strain, shape recovery rate, recovery stress, shape recovery temperature range, "transformation", "reorientation" and "dislocation" (true) yield stresses. Conventional thermomechanical treatment (TMT) has made it possible to significantly improve shape memory and superelasticity stress-strain characteristics of Ti-Ni alloys while offering an effective control of their shape recovery temperature range [1, 7-21]. This TMT combines cold-, warm- or hotdeformation of a moderate intensity (accumulated strains ranging from 20 to $40 \%$ ) with a certain post-deformation annealing (PDA), with the objective of creating in these alloys a polygonized dislocation substructure (subgrain size ranging from 0.1 to $1 \mu \mathrm{m}$ and grain size, from 5 to $50 \mu \mathrm{m}$ ) $[1,22]$. However, by the early 2000s, nearly all the resources offered by conventional TMT technology had been exploited.

A promising opening for the further improvement of SMA functional properties was identified in using severe plastic deformation (SPD) techniques to produce ultrafine grained, i.e., nanocrystalline (NC, grain size below $100 \mathrm{~nm}$ ) or submicrocrystalline (SMC, grain size from 100 to $1000 \mathrm{~nm}$ ) structures $[23,24]$. The main structural elements of these ultrafine materials are surrounded by highangle boundaries, and therefore belong to the category of true grains (crystallites), as distinct from subgrains in polygonized dislocation substructures surrounded by low- 
angle boundaries. (Note that the first application of SPD technologies to form NC structures in Ti-Ni SMA was reported since as early as 1983 [25-28].

Starting from these seminal publications, a series of works has been dedicated to the determination of the thermomechanical conditions under which the NC structure appears, transforms, and disappears in Ti-Ni-based SMA. Electron microscopy studies of the near-equiatomic Ti-Ni alloys subjected to high-pressure torsion $[8,11,26$, 29-33], cold rolling [25, 28, 34-36], and compression [34] SPD techniques revealed that the NC structure formation starts at a certain deformation intensity (true strain of about $e=0.5$ ). When the applied deformation strain increases above this level, the NC formation progresses, accompanied by gradual structure amorphization.

The potential for the amorphous structure to be formed by SPD depends on the relative positions of the deformation temperature and the temperature range of martensitic transformation: it is strongest when the deformation temperature is below $M_{\mathrm{f}}$ (initial stable martensite), intermediate when the deformation temperature lies somewhat above $M_{\mathrm{s}}$ (initial metastable austenite in a premartensitic state), and weakest when the deformation temperature is far above $M_{\mathrm{S}}$ (initial thermally stable austenite). The increase of the initial lattice imperfectness and the resistance to plastic deformation by lattice mechanisms with decreasing deformation temperature plays an important role in this dependence [31].

When the amorphized structure is subjected to PDA in the $150-400{ }^{\circ} \mathrm{C}$ temperature range, it crystallizes into the NC structure [8, 11, 29, 37-39]. When the PDA temperature increases, the grains of the NC structure, formed as a result of either deformation or crystallization, coarsen [8, 11, 29, 37, 38, 40].

High-pressure torsion (HPT) experiments demonstrate the following regularities of structure formation as a function of thermomechanical deformation conditions [31]. Raising the deformation temperature to the austenite temperature range suppresses amorphization because of the following reasons: at higher temperatures, the resistance to plastic deformation decreases, the interval between the deformation and the $M_{\mathrm{s}}$ temperatures becomes greater, and the lattice diffusion takes place. The highest deformation temperature for the partial amorphization of $\mathrm{Ti}-\mathrm{Ni}$ with the highest $M_{\mathrm{s}}$ temperature lies at about $300{ }^{\circ} \mathrm{C}$, the lower the $M_{\mathrm{s}}$ of this alloy, the lower this temperature. Thus, the rise of deformation temperature promotes direct nanocrystalline structure formation up to a certain temperature threshold, above which the grain size evolves from nano-metric $(<100 \mathrm{~nm})$ to submicrometric (100 nm to $1 \mu \mathrm{m})$ range. This limiting temperature is about $300-350{ }^{\circ} \mathrm{C}$ for non-aging equiatomic Ti-Ni alloys, and somewhat above $400{ }^{\circ} \mathrm{C}$ for aging hyper-equiatomic Ti-Ni alloys. In the last case, precipitated particles delay grain growth.

Note also that applying a very popular equal channel angular pressing (ECAP) SPD technique to form true NC structures in Ti-Ni SMA was not successful: ECAP even at the lowest possible temperature of $350{ }^{\circ} \mathrm{C}$ only resulted in the formation of SMC structures [41]. The results of the HPT experiment and comparison of the HPT and ECAP processes make it clear that to obtain the true nanocrystalline structure at such high temperatures, it would be necessary to provide continuous SPD process and eliminate inter-pass gaps and annealing, the latter being actually an integral parts of a ECAP schedule.

The practical significance of all of this accumulated knowledge has become clearer after a series of publications that showed a significant improvement of a whole combination of the Ti-Ni SMA functional properties due to the $\mathrm{NC}$ structure formation as a result of $\mathrm{CR}+\mathrm{PDA}$ procedure [42-44]. Starting from that point, extensive studies of the thermomechanical conditions for nanostructure formation in products suitable for practical applications have been realized. The results of these works are generalized and discussed in this paper. The results of studies of nanostructures formation and evolution under conditions of cord drawing and PDA are in line with those for CR + PDA, and therefore they are not specifically described in this review. For their details, see [45, 46].

\section{Methodology and Selected Results}

A set of systematic studies was carried out on Ti-Ni alloys with Ni content varying from 50 to 50.7 at.\%. The wire specimens were annealed at $700-800{ }^{\circ} \mathrm{C}$ (recrystallization annealing) and water-cooled. Next, they were cold rolled at room temperature with moderate (logarithmic thickness reduction of $e=0.25-0.5)$, intermediate $(e=0.7-1.0)$, and severe $(e=1.12-2.11)$ levels of deformation intensity, annealed in the $200-700{ }^{\circ} \mathrm{C}(1 \mathrm{~h})$ temperature range and water-cooled.

\section{Structure and Microhardness of Ti-Ni Alloys as Functions of CR Intensity}

Since any TMT schedule combines two main stages, CR and PDA, the changes in the material structure during deformation are of primary interest, as these very changes are responsible for the structural and chemical conditions that lead to the creation of nanostructures in the course of post-deformation annealing.

$\mathrm{X}$-ray diffraction analysis allows an integral estimation of the structure, substructure, and phase composition. Five X-ray lines of the monoclinic $B 19^{\prime}$-martensite can be 
distinguished in the diffractogram of the quenched alloy (Fig. 1) [36]. A small (up to $5 \%$ ) amount of the retained $B 2$-austenite is also present. The conventional CR deformation ( $e=0.25$ ) leads to a considerable broadening of the martensite X-ray diffraction lines due to an increase in the dislocation density and the appearance of a crystallographic texture, the latter resulting in a substantial growth of the relative intensity of the $(111)_{\mathrm{B} 19^{\prime}}$ and $(110)_{\mathrm{B} 19^{\prime}}$ lines. Although the amount of martensite decreases with increasing CR strain, after the largest strain of $e=2.11$, a sufficiently large amount of martensite remains. This can also be observed from the retained distinct "shoulder" formed by the superposed broadened lines $(110)_{\mathrm{B} 19^{\prime}}$ and $(002)_{\mathrm{B} 19^{\prime}}$ on the left side of the common broadened peak (see Fig. 1).

When the deformed alloys are heated in a DSC chamber after conventional $\mathrm{CR}(e=0.25)$, only one endothermic peak is observed, which corresponds to the reverse $B 19^{\prime} \rightarrow B 2$ transformation (Fig. 2a). The peak temperature is considerably higher than the peak temperature of the quenched alloy $\left(75^{\circ} \mathrm{C}\right)$, which is the result of the stabilization of the plastically deformed martensite [36]. Upon heating after the $e=0.5$ strain, two peaks are detected: the first, located near $160{ }^{\circ} \mathrm{C}$, is endothermic and is weaker and wider than it is after $e=0.25$, whereas the second peak (about $350{ }^{\circ} \mathrm{C}$ ) is also wider and weaker, than it is after $e=0.25$, but it is exothermic. The first peak apparently corresponds to the reverse martensite transformation, while the second peak is due to crystallization of the amorphous phase and nano-sized grain growth [47]. Note that when sufficiently high amorphous phase fraction forms $(e \geq 0.72)$ as a result of the initial $\mathrm{CR}$, an extended exothermic effect adjoining the crystallization/grain growth peak from the lower temperatures is observable (Fig. 2a). This effect can be attributed to structure relaxation processes in the amorphous phase (see [48] for details). With a further increase of CR strain $(e=1.12)$, the first peak becomes weaker and wider even more, and it is shifted toward higher temperatures, which is an indication of increasing martensite stabilization, while the second peak grows, narrows, and gradually shifts toward the higher temperatures.

When CR strain exceeds $e=1.12$, the first peak becomes so weak and broadened that it is almost unnoticeable. When strain increases even more, the critical temperature (the start temperature of the exothermic heat effect) continues its shift upward, and the peak itself becomes narrower. A quantitative estimation of the quantity of the amorphous phase was performed by comparing the magnitudes of the crystallization thermal effect between the severely deformed and the completely amorphous, melt-quenched, Ti-Ni alloys [36]. It should be noted that the aforementioned exothermic effect is caused not only by the nanocrystallization of the amorphous phase, but also by grain growth in the range of sizes in which the reduction of the grain boundaries area results in a significant heat release (from $<10$ to $100 \mathrm{~nm}$ ) [47].

To estimate the amount of the amorphous phase, it was assumed that the relative contribution of the two concomitant processes (crystallization and grain growth) to the total thermal effect is identical for the mixed
Fig. 1 Variation of X-ray diffraction patterns of the Ti$50.26 \mathrm{Ni}$ alloy with increasing $\mathrm{CR}$ strain after quenching $(e=0)$ (adapted from [36])

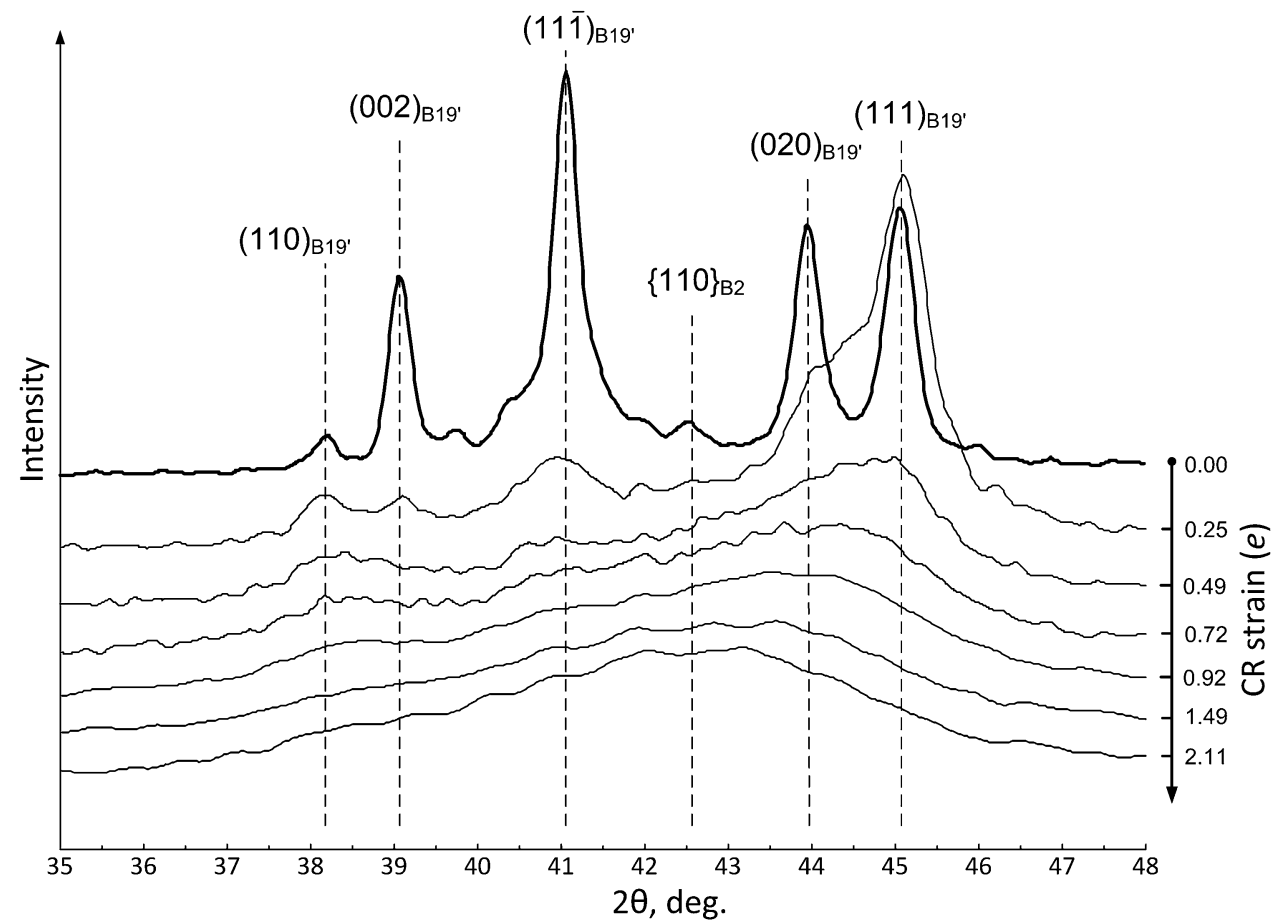



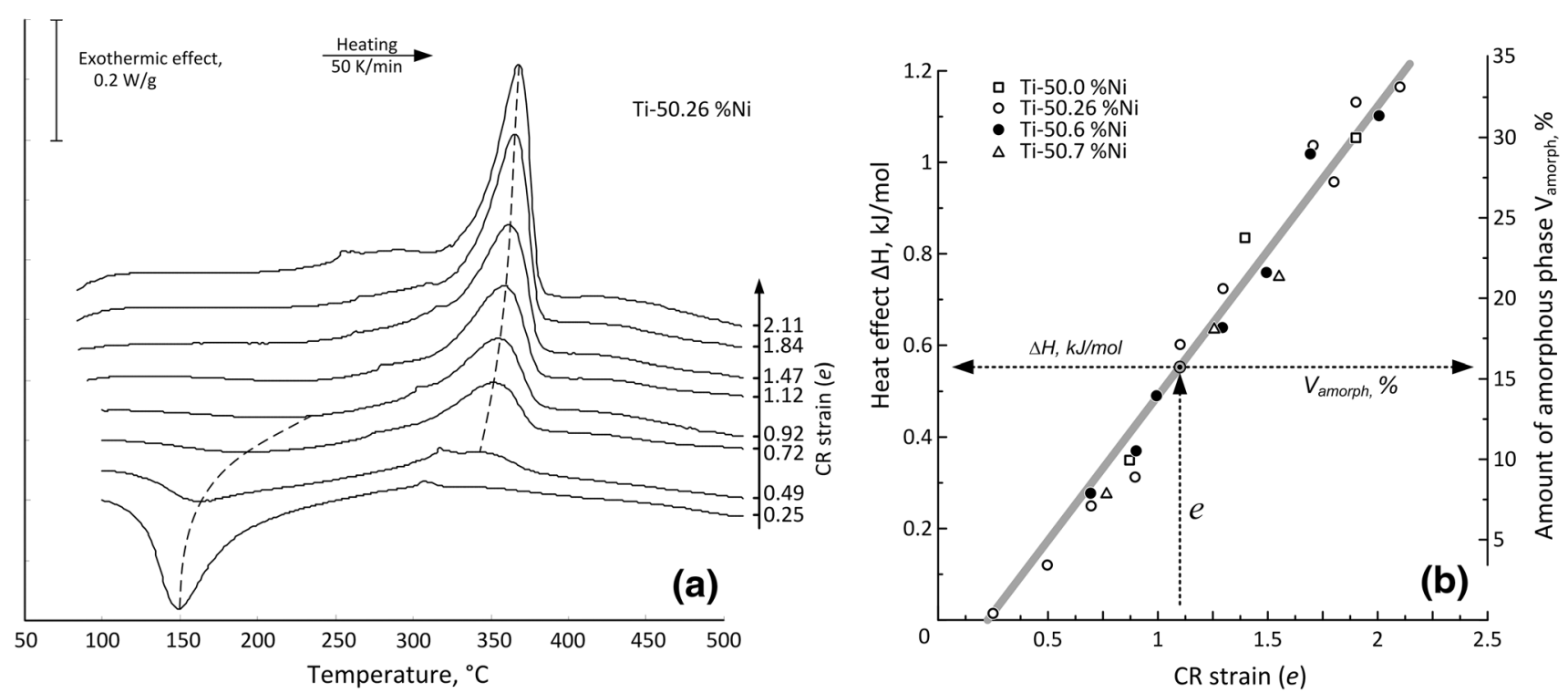

Fig. 2 DSC heating curves of the Ti-50.26\% Ni alloy (a) and amount of amorphous phase in Ti-Ni alloys estimated from the relative value of the thermal effect of crystallization and grain growth (b) after different CR strains (adapted from [36])

amorphous + crystalline and for the completely amorphous structures. The dependence of the amount of the amorphous phase on the initial deformation constructed under this assumption is plotted in Fig. 2b. It follows that an increase in $\mathrm{CR}$ strain from $e=0.50-2.1$ leads to a proportional increase in the amount of the amorphous phase from approximately 5 to $30-35 \%$.

Figure 3 displays the variation of the Vickers microhardness HV of Ti-50.0, Ti-50.26 (both initially martensitic), and Ti-50.6\% Ni (initially mainly austenitic) alloys when deformation strain increases. It is evident that the laws governing the changes in microhardness of these alloys are very close and that they practically reproduce the changes in the width of the X-ray diffraction lines. The insets in Fig. 3 show characteristic electron microscopic images and diffraction patterns of the Ti-50.0 \% Ni alloy obtained after conventional deformation ( $e=0.3$, a well-developed dislocation substructure of martensite and austenite), severe deformation $(e=1.9$, a mixture of nanocrystalline and amorphous structures), and intermediate deformation ( $e=0.88$, a mixture of all three structures) [42]. The SAED patterns in the last two cases represent halo rings with superposed reflections from their crystalline phases.

\section{Structure, Mechanical, and Functional Properties as Functions of PDA Temperature}

\section{Nanocrystalline Structure Formation}

Cold rolling (CR) under severe plastic deformation conditions $(e=1.7-1.9)$ creates a mixed amorphous-

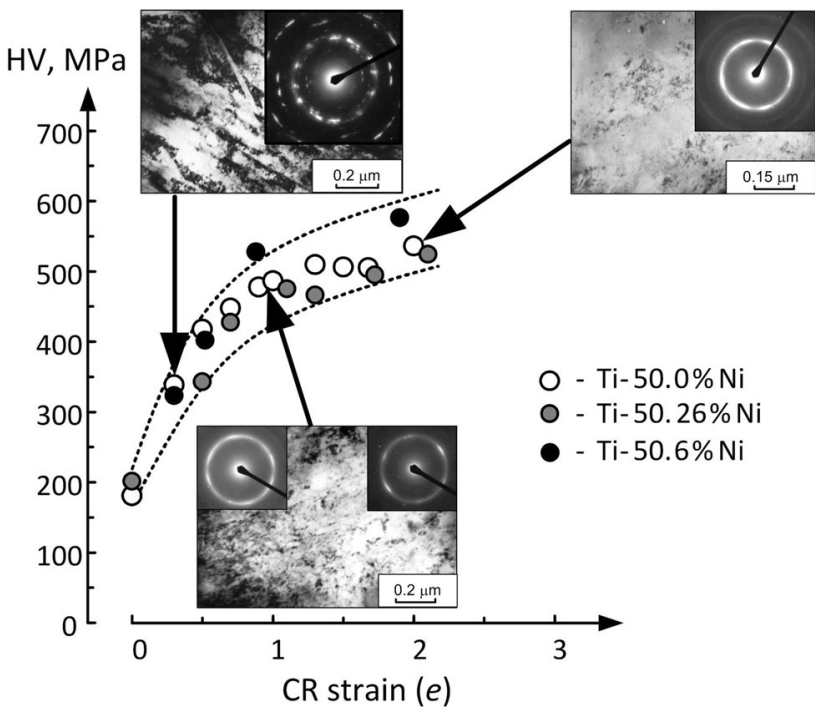

Fig. 3 Variation of the microhardness of Ti-Ni alloys with CR strain increase and transition from the developed dislocation substructure to a mixture of nanocrystalline and amorphous structures. The insets show the electron microscopic images of the structures and the electron diffraction patterns for Ti-50.0\% $\mathrm{Ni}$ alloy (adapted from [36])

nanocrystalline austenite structure shown in Fig. $4 a$ and $b$ for Ti-50.0 Ni and Ti-50.7 $\mathrm{Ni}$ alloys. Upon PDA up to $400{ }^{\circ} \mathrm{C}$, the amorphous matrix crystallizes into a nanocrystalline austenite structure (Fig. $4 \mathrm{c}-\mathrm{e}$ ). The corresponding SAED pattern represents the diffraction rings formed by the reflections of chaotically oriented nanograins. Further increase of PDA temperature results in a gradual growth of austenite nanograins (pure $B 2$-austenite 


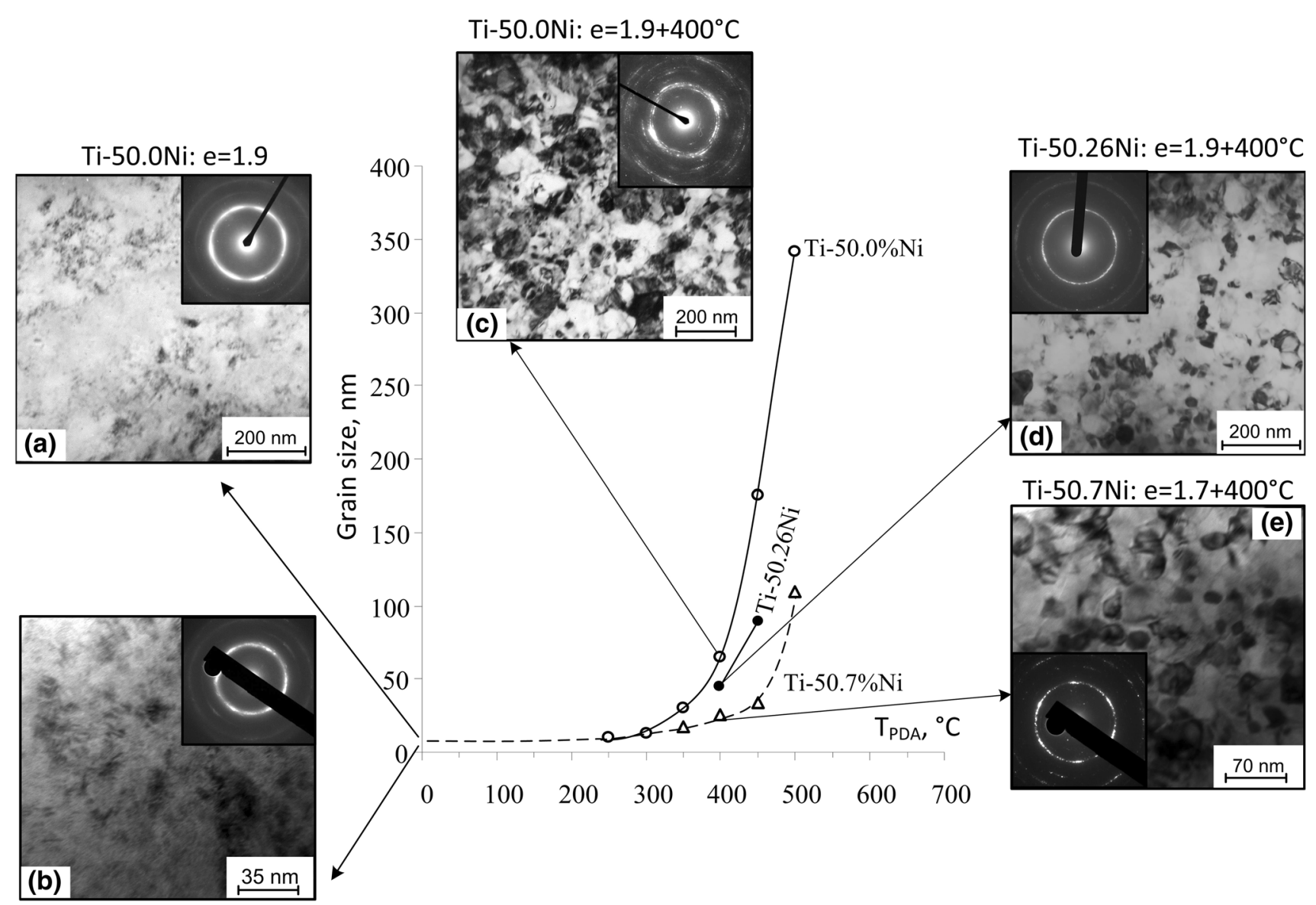

Ti-50.7Ni: e=1.7

Fig. 4 Grain size of severely deformed Ti-50.0 Ni (circle), Ti-50.26 $\mathrm{Ni}$ (filled circle), and Ti-50.7 Ni (triangle) alloys as a function of the PDA temperature; TEM images and SAED of corresponding

in Ti-50.7 $\mathrm{Ni}$ and $\mathrm{Ti}-50.26 \mathrm{Ni}$, and $B 2$-austenite $+B 19^{\prime}$ martensite in Ti-50.0\% Ni), which are free of high dislocation density (Fig. 4c-e). As a result of the further increase in PDA temperature, austenite nanograins formed as a result of deformation and crystallization grow, and the structure gradually transforms from NC to SMC.

Figure 4 shows that grains in Ti-50.7 $\mathrm{Ni}$ alloy grow much slower than grains in Ti-50.0 Ni alloy. This phenomenon is caused by the blocking effect of fine $\mathrm{Ti}_{3} \mathrm{Ni}_{4}$ particles on the migration of dislocations, sub-boundaries and grain boundaries in the austenite structure of the nickel-rich alloy. It is known that the temperature range in which intensive precipitation of the $\mathrm{Ti}_{3} \mathrm{Ni}_{4}$ phase occurs in the quenched alloy ranges from 400 to $600{ }^{\circ} \mathrm{C}$ $[1,3]$. Strain hardening accelerates the precipitation process. Note that for both Ti-50.0 and Ti-50.7 Ni alloys, the grains of the nanocrystalline structure are much finer than the subgrains of the polygonized substructure resulted from conventional CR + PDA processing [43, 49]. structures before PDA: a Ti-50.0 Ni $(e=1.9)$ and b Ti-50.7 Ni $(e=1.7)$; after PDA: c Ti-50.0 Ni $\left(e=1.9+400{ }^{\circ} \mathrm{C}\right)$, d Ti-50.26 $\mathrm{Ni}\left(e=1.9+400{ }^{\circ} \mathrm{C}\right)$, e $\mathrm{Ti}-50.7 \mathrm{Ni}\left(e=1.7+400^{\circ} \mathrm{C}\right)$

Phase Transformation, Crystallization, and Grain GrowthRelated Heat Effects

It can be observed from Fig. 5 that for severely cold-rolled Ti-50.26 $\mathrm{Ni}$ alloy samples ( $e=1$ and 1.72), up to annealing at $250{ }^{\circ} \mathrm{C}$, the higher the PDA temperature, the higher the exothermic heat flow [50]. When PDA temperature exceeds $325{ }^{\circ} \mathrm{C}$, heat flow changes sign from positive (exothermic) to negative (endothermic), while it is always decreasing and endothermic for the moderately cold-rolled samples (Fig. 5). The phenomenon of the initial increase in heat flow can be explained by the strongly heterogeneous structures of the cold-rolled and annealed samples and the resulting from that two coinciding transformations: (a) crystallization of the amorphous phase, and (b) growth of the existing nanocrystals [47].

Furthermore, in severely cold-rolled alloys with mixed amorphous-nanocrystalline structure, the dominant processes during annealing at relatively low temperatures are nucleation (i.e., nanocrystallization of amorphous phase) and 
Fig. 5 Heat flow after CR $(0.3$, 1.0 , and 1.72) and annealing at $100-700{ }^{\circ} \mathrm{C}(1 \mathrm{~h})$ of $\mathrm{Ti}-50.26$ $\mathrm{Ni}$ alloy

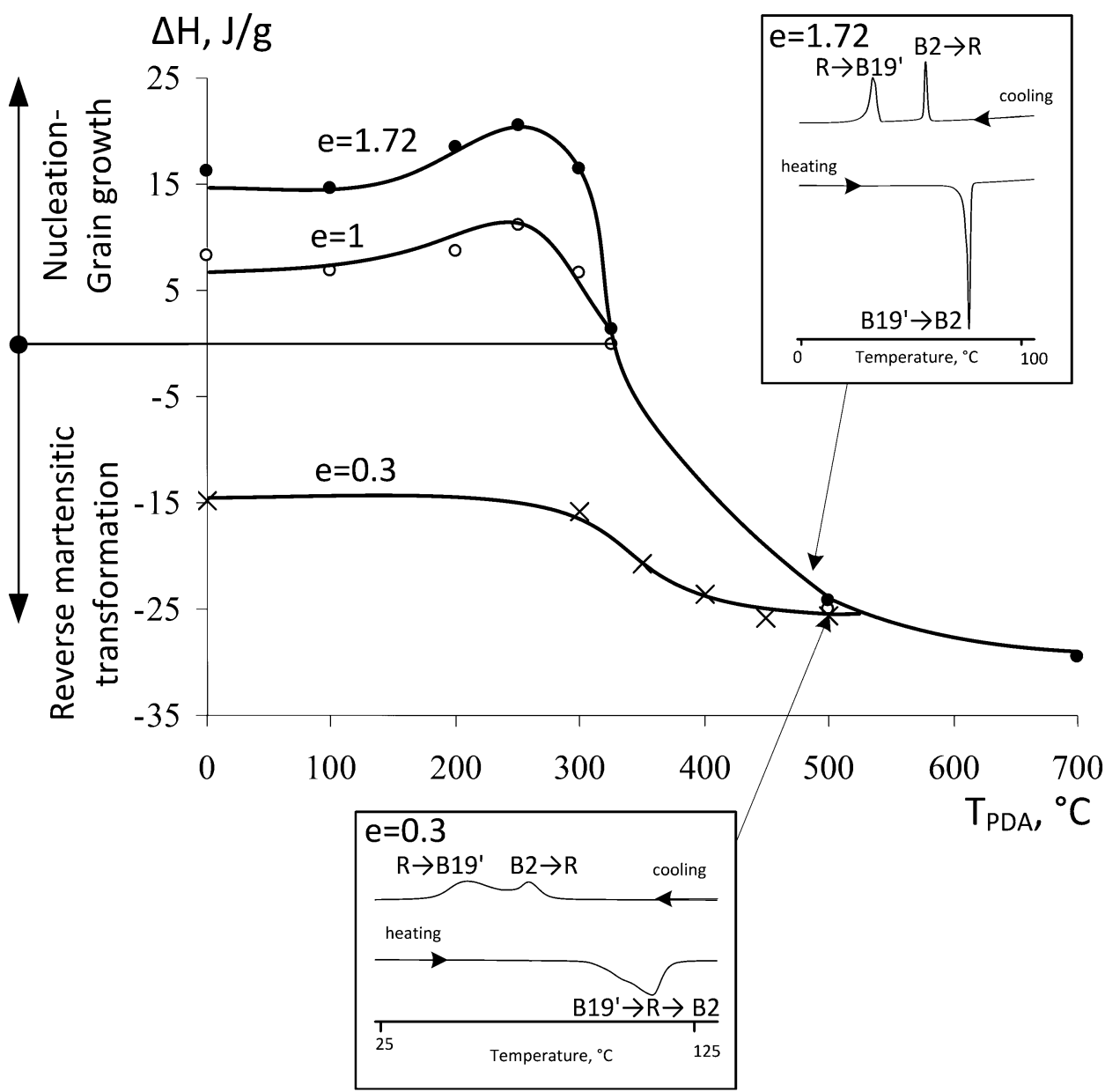

grain growth. In moderately cold-rolled alloys, the dominant processes are stress relaxation and recovery, followed by polygonization and recrystallization of $B 2$-phase. The difference help explain why, for severely cold-rolled alloys $(e=1$ and 1.72), after annealing at temperatures under $325{ }^{\circ} \mathrm{C}$, exothermic heat flow related to nucleation and grain growth is observed, whereas after annealing at higher temperatures (and at any temperature, for moderately CR alloys, $e=0.3$ ), endothermic heat flow due to reverse martensitic transformation is measured [50]. Note also that the welldeveloped dislocation substructure contains more obstacles for martensitic transformation than the structure crystallized from its amorphous precursor (severe CR + PDA processing). This nanocrystalline structure is almost exempt of dislocations, which is illustrated by its much narrower DSC peaks compared to its polygonized counterpart (see the DSC inserts in Fig. 5). Note that the thermomechanical treatment which creates a well-developed dislocation substructure, including a polygonized/nanosubgrained substructure, or nanocrystalline structure, while suppressing the B19'martensite formation, facilitates formation of intermediate R-phase on cooling [1, 8, 42, 51].

\section{Microhardness Evolution and Inverse Hall-Petch Effect}

Observe that the evolutions of microhardness as a function of the deformation strain and PDA temperature (Fig. 6) are almost identical to those of latent heat (Fig. 5): an increase in annealing temperature after $e=0.3$ leads to continuous material softening, whereas for severely cold-rolled alloys ( $e=1$ and 1.72), an increase in annealing temperature up to $250-300{ }^{\circ} \mathrm{C}$ leads to a significant increase in microhardness, followed by its drastic decrease, when this temperatures range is exceeded (Fig. 6a) [50]. This means that both the $\mathrm{HV}\left(T_{\mathrm{PDA}}\right)$ and $\Delta H\left(T_{\mathrm{PDA}}\right)$ behaviors are related to the same changes in the material microstructure.

The mechanical properties of metallic alloys are dependent upon all of the structural parameters, such as grain and subgrain size, phases in presence, lattice defects, precipitates, impurities, etc. Grain size alone thus cannot be considered as the only parameter governing the mechanical properties of metallic alloys, and this is especially true for Ti-Ni shape memory alloys undergoing thermoelastic martensitic phase transformations. On the other hand, the $B 19^{\prime}$-martensite formation on cooling (but not under stress) 


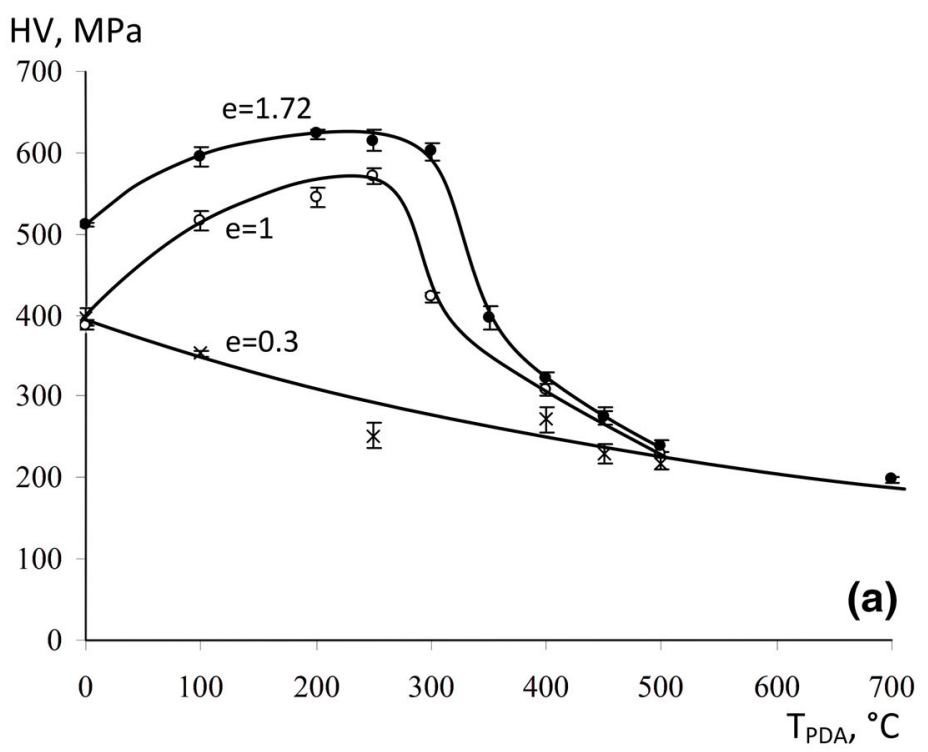

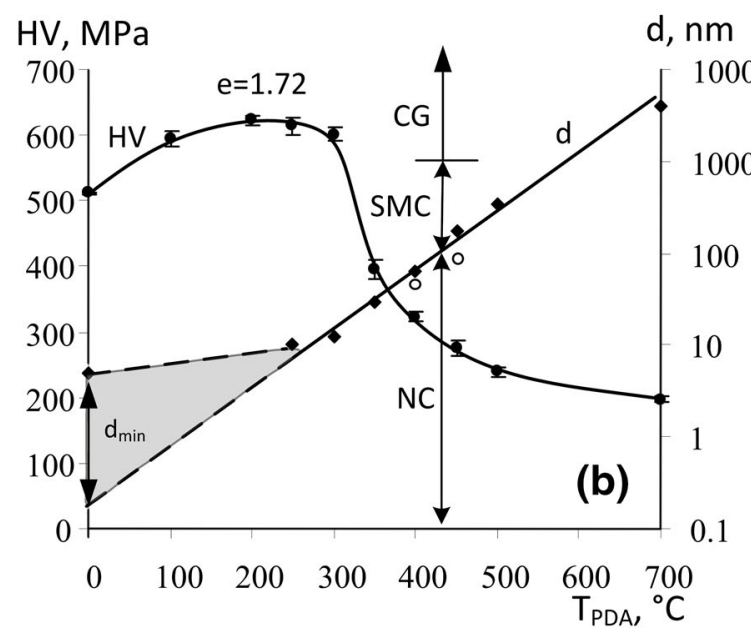

Fig. 6 Comparison of $\mathrm{HV}$ and grain size evolutions: a HV evolution as a function of the CR intensity and PDA temperature for Ti-50.26 $\mathrm{Ni}$ alloy; b HV and grain size as functions of the PDA temperature after severe CR (circle-Ti-50.26 Ni, $e=1.72$, filled circle-Ti-50.0

is suppressed in $\mathrm{Ti}-\mathrm{Ni}$ when the grain size is less than $30-50 \mathrm{~nm}$ [8], and thus the grain size can be the major structural parameter to consider after severe plastic deformation and PDA below $450{ }^{\circ} \mathrm{C}$ [47].

In Fig. 6b, the $\mathrm{HV}\left(T_{\mathrm{PDA}}\right)$ plot obtained for Ti-50.26 Ni $(e=1.72)$ is superposed on the $d\left(T_{\mathrm{PDA}}\right)$ plot for Ti-50.26 $\mathrm{Ni}(e=1.72)$ and $\mathrm{Ti}-50.0 \mathrm{Ni}(e=1.9)$, and a combined $\mathrm{HV}(d)$ graph is plotted in Fig. 6c. Note that the grain size measurements were performed by TEM for $T_{\mathrm{PDA}}$ $\geq 250{ }^{\circ} \mathrm{C}[36,49]$. Since the structure of the severely cold-worked alloy is a mixed nanocrystalline and amorphous structure, it is reasonable to suppose that the size of a representative structural parameter varies in the triangular grey-shaded zone shown on Fig. 6a and b. This zone is upper-bound by a line representing an

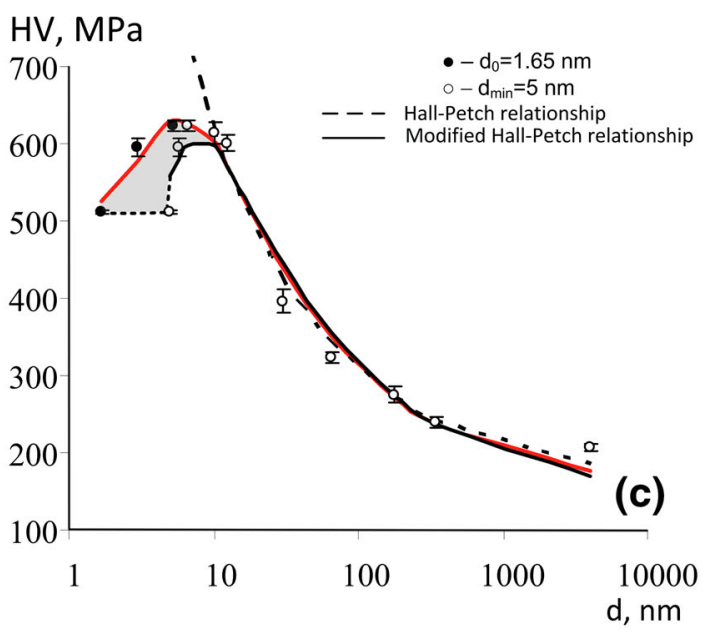

$\mathrm{Ni}, e=1.9)$ [36, 46]; $N C$ nanocrystalline, $S M C$ submicrocrystalline, $C G$ coarse-grained; c combined "HV-d" graph for $d_{0}=1.65$ and $d_{\min }=5 \mathrm{~nm}$

extrapolation of the grain size for $T_{\mathrm{PDA}}=250{ }^{\circ} \mathrm{C}$ $(12.5 \mathrm{~nm})$ to $T_{\mathrm{PDA}}=0{ }^{\circ} \mathrm{C}\left(d_{\min }=5 \mathrm{~nm}\right)$ [52], and it is lower-bound by a line representing an extrapolation of all the measured $d-T_{\mathrm{PDA}}$ data at $T_{\mathrm{PDA}}>250{ }^{\circ} \mathrm{C}$ to $T_{\mathrm{PDA}}=0{ }^{\circ} \mathrm{C}\left(d_{0}=1.65 \mathrm{~nm}\right.$ - the minimum crystal size when almost all of its atoms are located on its surface) calculated in accordance with [52].

Thus, an abnormal Hall-Petch relationship is observed in $\mathrm{Ti}-\mathrm{Ni}$ shape memory alloy with nanocrystalline structure obtained by SPD and PDA, and the critical grain size for the normal-abnormal Hall-Petch relationship transition is around $10 \mathrm{~nm}$ (Fig. 6c). The best correlation with the experimental data [50] was observed using the model of material softening based on the influence of interface regions [53, 54] (Fig. 6c). 
Critical Stresses (UTS, YS, Transformation stress) as Functions of Grain Size

For Ti-50.26 Ni alloy annealed at $400{ }^{\circ} \mathrm{C}(1 \mathrm{~h})$, the ultimate tensile strength (UTS), "dislocation" yield stress (YS) and "transformation" yield stress (critical stress for martensitic transformation, $\sigma_{\text {tr }}$ ) are plotted in Fig. 7 as functions of the logarithmic thickness reduction and grain size. Note that in this figure, $d^{*}$ corresponds to the size of grains with no distinction as to their origin: mainly crystallized from amorphous phase $(e \geq 1.2)$, grown from existing nanograins $(0.7<e<1.2)$, or polygonized from the initially deformed grains $(e<0.7)$. It can be observed that the smaller the grain size, the greater the value of all critical stresses, but the greatest difference between the plastic deformation and the phase transformation onset stresses corresponds to the grain size of approximately $100 \mathrm{~nm}$, i.e., to the alloy with nanocrystalline structure. This structure demonstrates therefore the highest potential for the complete realization of the crystallographic resource of recovery strain, since an increase in the YS$\sigma_{\text {tr }}$ window delays the appearance of unrecoverable strains.

\section{Static Versus Fatigue Functional Properties}

It was found that recovery strain in $\mathrm{Ti}-\mathrm{Ni}$ alloys after moderate $\mathrm{CR}(e=0.3)$ followed by PDA is much higher than after recrystallization annealing [43, 51]. When the CR strain increases, for example, from 0.3 to 1.9 , the completely recoverable strain shows even higher improvement. For example, changing the structure of Ti-

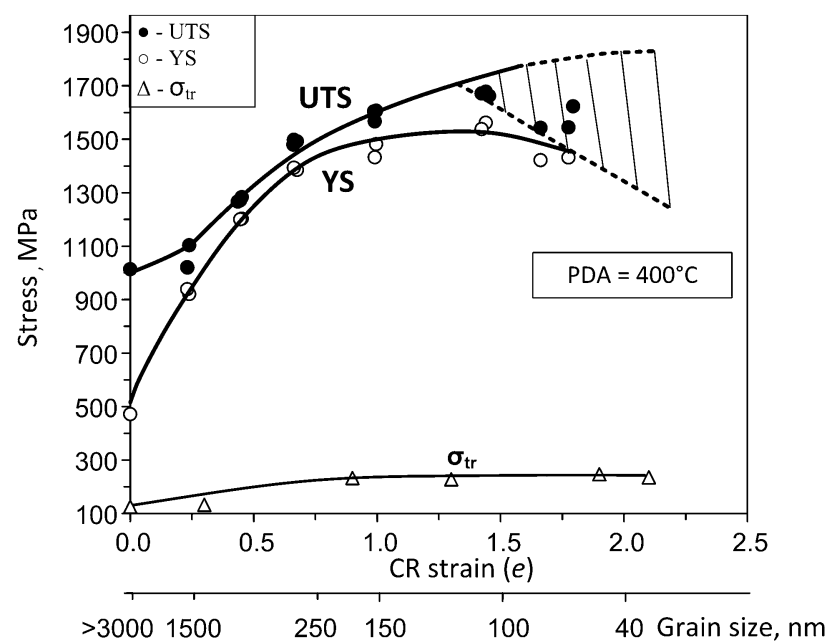

Fig. 7 Ultimate tensile strength (UTS), "dislocation" yield stress (YS) and transformation yield stress $\left(\sigma_{\mathrm{tr}}\right)$ as functions of the CR intensity and grain size $\left(d^{*}\right)$ for Ti-50.26 \% Ni alloy (PDA at $400{ }^{\circ} \mathrm{C}$, $1 \mathrm{~h})$
$50.0 \mathrm{Ni}$ alloy from a polygonized dislocation substructure, CR (0.3) + PDA $\left(350{ }^{\circ} \mathrm{C}\right)$, to a nanocrystalline, CR $(1.9)+\operatorname{PDA}\left(400{ }^{\circ} \mathrm{C}\right)$, results in a more than $20 \%$ increase of recoverable strain: from 6.5 to $8 \%$ (Fig. 8a). The maximum recovery stress is also strongly structuredependent. Increasing the CR strain from 0.3 to 1.9 results in a more than $30 \%$ increase of recovery stress: from 920 to $1420 \mathrm{MPa}$ (Fig. 8b). A nanosubgrained polygonized substructure, CR $(0.3)+\operatorname{PDA}\left(300{ }^{\circ} \mathrm{C}\right)$, provides recoverable strains almost as high as those of NC structure, but it does not improve recovery stress characteristics (Fig. 8a).

Thus, the realization of the highest combination of functional properties (completely recoverable strain and constrained recovery stress) is explained by the peculiarities of the nanocrystalline structure that forms during moderate-temperature annealing after severe plastic deformation [43, 51, 55]. First, the increase of the "dislocation" yield stress (YS) caused by nanocrystalline structure (40-80 nm) prevents plastic deformation during shape memory effect-inducing deformation [56]. Moreover, NC does not contain a developed dislocation substructure, contrary to a polygonized substructure, which promotes realization of the phase transformation-based deformation mechanisms in respect to the common slip plastic deformation mechanisms. PDA at higher temperatures leads to grain growth that softens austenite and alters the alloys functional properties.

As seen from [8], the cooling-induced $B 19^{\prime}$-martensite formation in $\mathrm{Ti}-\mathrm{Ni}$ is suppressed when the grain size is less than $30-50 \mathrm{~nm}, \mathrm{CR}(1.9)+\operatorname{PDA}\left(350^{\circ} \mathrm{C}\right)$, which is why in this case, despite very high recovery stresses, completely recoverable strains are significantly smaller than after PDA at $400{ }^{\circ} \mathrm{C}$. In the case of the moderate plastic strain, $\mathrm{CR}$ $(0.3)+$ PDA $\left(<300{ }^{\circ} \mathrm{C}\right)$, both the completely recoverable strain and the maximum recovery stress decrease. This decrease is due to a partial suppression of martensitic transformation, but here it is mostly a consequence of the high dislocation density preserved by low-temperature annealing [41, 42]. Further decrease in PDA temperature leads to the formation of much smaller grains and preservation of the amorphous structure, with dramatically smaller recovery strains and stresses. Thus, the best combination of the functional properties of $\mathrm{Ti}-\mathrm{Ni}$ alloys, i.e., the maxima of both completely recoverable strains and recovery stresses, are obtained after severe plastic deformation followed by PDA at $400{ }^{\circ} \mathrm{C}$, which creates a nanocrystalline austenite structure with grain size in the 40-80 nm range.

However, achieving only high "static" functional properties is not enough since industrial applications require not only a high level of the recovery stress-strain characteristics, but also their stability and longevity during multiple operations [57]. In Fig. 9, the recovery stresses 
Fig. 8 Functional properties (recovery stress and recovery strain) of Ti-50.0\% Ni as functions of the PDA temperature after a CR (0.3) and b CR (1.9). The TEM images are shown for the TMT conditions corresponding to the maximum attainable recovery stress/strain values:

a $e=0.3+T=350{ }^{\circ} \mathrm{C}$ and b $e=1.9+T=400{ }^{\circ} \mathrm{C}$

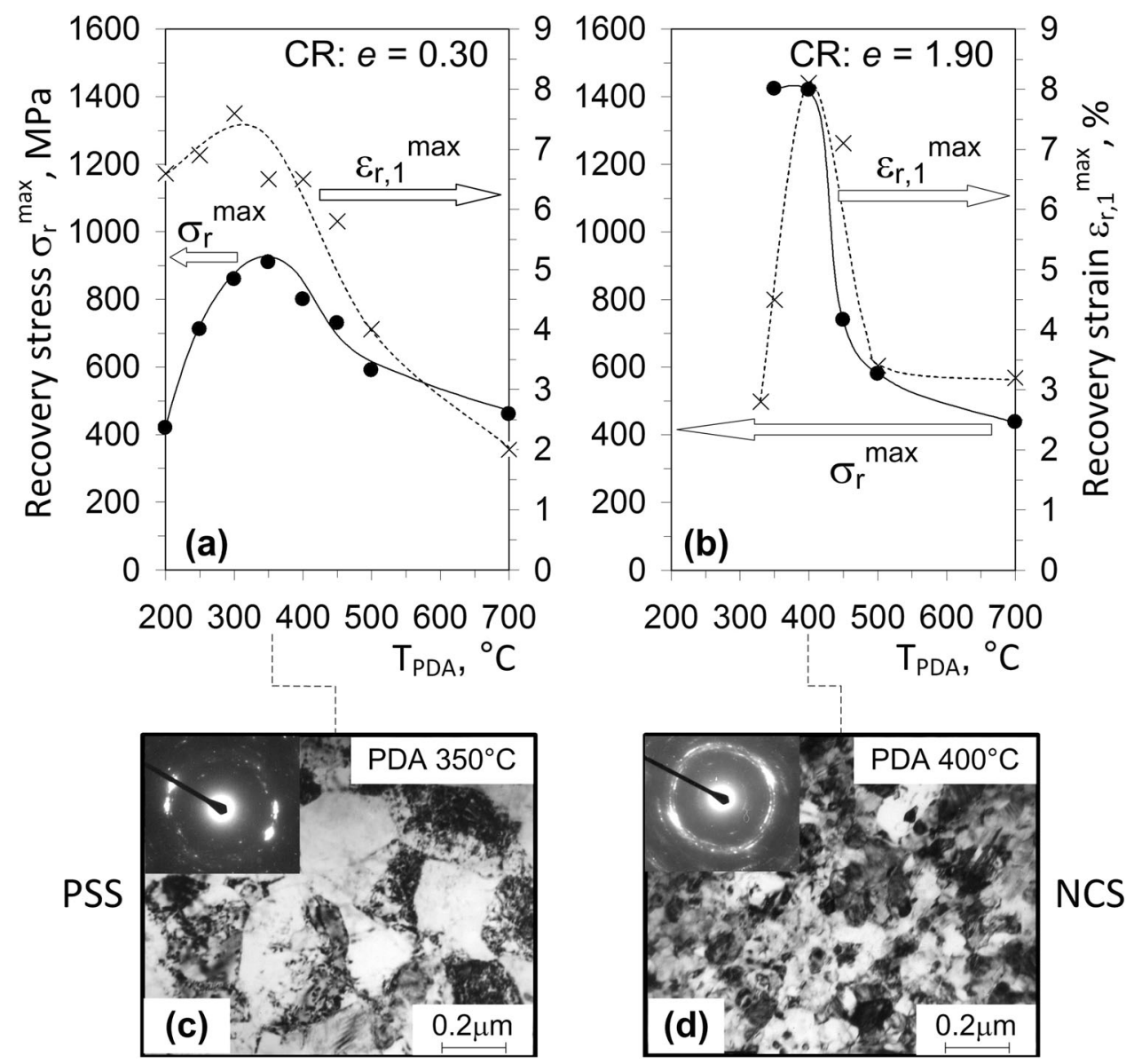

measured for the 1st and the 500th cycle of recovery stress generation/relaxation repetitive testing is plotted as a function of CR strain (PDA at $400{ }^{\circ} \mathrm{C}, 1 \mathrm{~h}$ ). In the same figure, the number of cycles to failure is also plotted as a function of the same parameter. It can be observed that the greater the CR strain for the same PDA, the smaller the grain size, and the higher the recovery stress and its stability during testing. However, these high values are obtained at the cost of a shorter fatigue life. If the goal is to maximize the number of thermomechanical cycles, then plastic deformation of a moderate intensity should be applied, which will evidently entail lower levels of functional performances (smaller recovery strain/stress characteristics and less cyclic stability). An analogous conclusion follows from functional fatigue measurements under other testing modes: free-stress shape recovery, the assisted two-way shape memory effect and isothermal superelastic cycling [58, 59].

Two factors, or rather their combination, could explain the negative impact of higher CR intensity on the Ti-Ni alloy fatigue life: (a) processing-induced defects, such as microcracks observed on the edges of severely cold-rolled strips [59, 61], and (b) smaller resistance to the fatigue

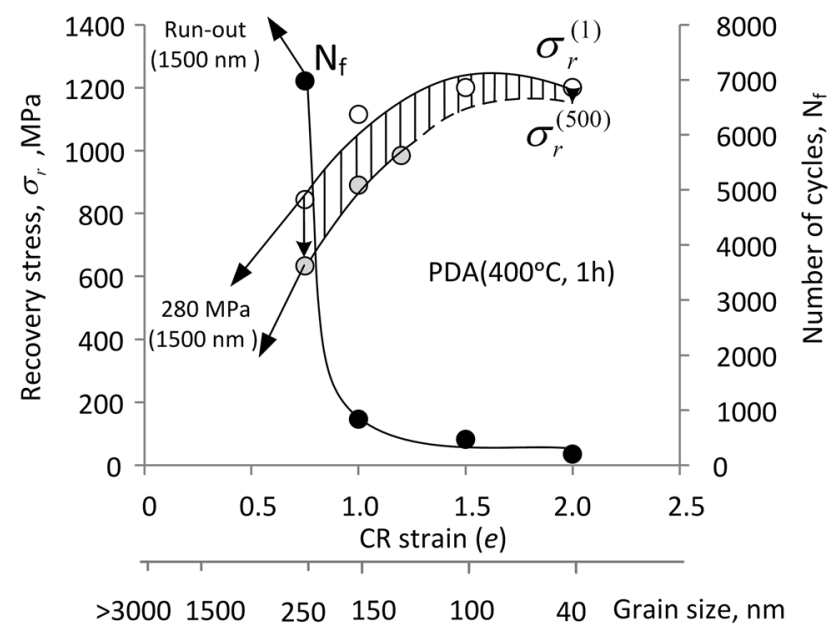

Fig. 9 Maximum recovery stress (the 1st and the 500th cycle) and the number of cycles to failure after PDA at $400{ }^{\circ} \mathrm{C}$ as functions of the CR strain and grain size (Ti-50.26\% Ni) [56-62]

cracks propagation inherent to some ultrafine-grained materials [61].

The simplest way to limit processing-induced damage, while preserving the possibility of forming nanocrystalline 
Fig. 10 Influence of different TMT schedules on the texture and functional properties of Ti$50.26 \%$ alloy: a maximum completely recoverable strain (single actuation) and corresponding inverse pole figures; b recovery stress (single actuation); $\mathbf{c}$ functional fatigue life; and d cyclic stability. $\mathrm{O}$ $[011]_{\mathrm{B} 2}$ pole, $\mathrm{X}$-IPF maximum
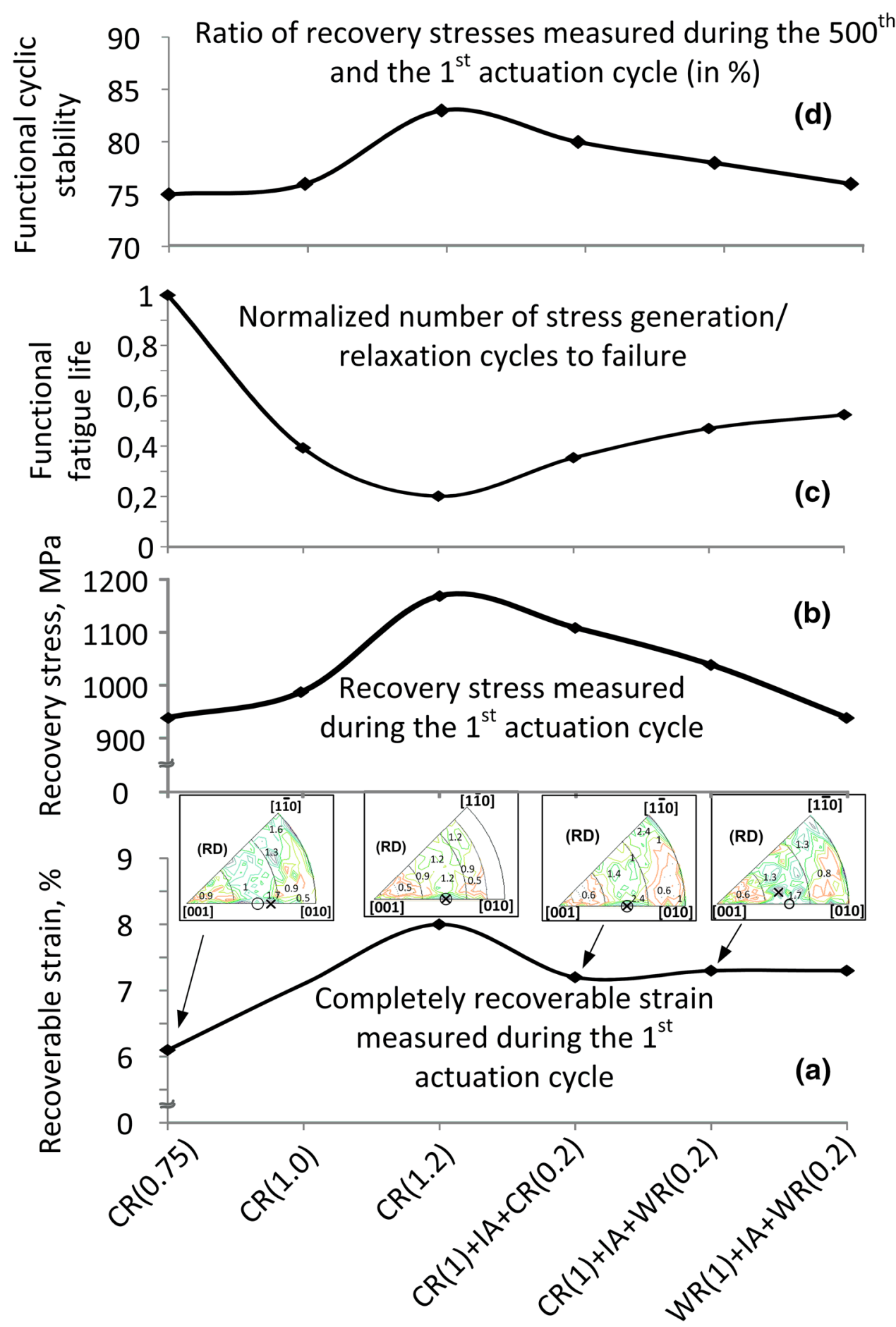

structure, is to increase rolling temperature and introduce intermediate annealing (IA) in the TMT multi-pass schedule [59, 61]. With this objective, a series of TMT schedules were compared under the following common conditions: warm rolling (WR) temperature corresponding to $150{ }^{\circ} \mathrm{C}$, and intermediate and final annealing treatment temperature and time corresponding to $400{ }^{\circ} \mathrm{C}$ and $1 \mathrm{~h}$ [63].
Some of the results of this study are collected in Fig. 10, where the static and fatigue functional performances and inverse pole figures (IPF) of B2-austenite are compared for all of the TMTs containing CR, WR, and IA steps in various combinations, each followed by PDA at $400{ }^{\circ} \mathrm{C}(1 \mathrm{~h})$. It follows from the IPF analysis that the main texture component is $\left.\{100\}\langle 110\rangle_{\mathrm{B} 2}\right)$ after all of the TMT schedules [59, 62]. This means that the preferred orientation of 
the B2-austenite lattice is equally favorable for maximum recovery strain realization in all of the cases, and that texture is not really a decisive factor in the realization of static and fatigue SMA properties.

The highest recovery stress and completely recoverable strain values are measured for the entirely cold-worked alloy with mainly $\mathrm{NC}$ structure $(e=1.2)$. The same accumulated strain of 1.2 , but with limited CR contribution, CR (1) + IA + WR (0.2) + PDA (400 $\left.{ }^{\circ} \mathrm{C}\right)$, allowed a radical decrease in microcrack size and concentration, while preserving significant structure refinement. Moreover, the resulted from the first deformation-annealing sequence, a mixed $\mathrm{NC}+\mathrm{NS}$ structure contributed to higher low-temperature deformability of the material during the last WR (0.2) step [64, 65]. As a result of these combined factors, it is clear that after CR (1) + IA + WR (0.2), the fatigue life that is twice as long as after CR (1.2); the price being again somewhat lower level and cyclic stability of recovery stresses and strains.

Finally, the hypothesis that nanocrystalline Ti-Ni-based SMA can be inherently less fatigue-resistant than their coarser-grained counterparts has been dismissed by our recent study that compared the fatigue resistance of specimens with NC, SMC, and mixed structures [61]. This study has clearly shown that nanocrystalline structure should lead to the highest fatigue resistance of Ti-Ni SMA, provided it is free of processing-induced defects.

\section{Conclusions}

1. For Ti-Ni SMAs, the formation of an optimum nanocrystalline structure with grain size of $40-80 \mathrm{~nm}$ as a result of annealing after severe plastic deformation by cold rolling (true strain $e=1-2$ ) results in the best combination of static functional properties (maximum completely recoverable strain and recovery stress values) which is not achievable for the recrystallized structure or polygonized (including nanosubgrained) substructure.

2. Grain refinement of the $\mathrm{NC}$ structure below $40 \mathrm{~nm}$ results in the suppression of martensite formation, and thus radically decreasing the level of completely recoverable strains, while keeping recovery stresses high. The grain coarsening above $100 \mathrm{~nm}$ rapidly decreases the level of both the maximum completely recoverable strains and recovery stresses due to a rapid decrease in the difference between the "dislocation" (true) and transformation yield stresses.

3. During multi-cycle superelastic and shape memory testing, NC alloys demonstrate a higher functional stability than their coarser-grained counterparts. The smaller the grain size, the greater the cycling stability, but the lower the functional fatigue resistance, mainly because of the cold work-induced defects. However, according to the latest findings, the fatigue life of $\mathrm{Ti}-$ Ni SMA free from processing-induced defects and with a grain size ranging from 40 to $100 \mathrm{~nm}$ should be longer than that of their coarser-grained counterparts.

4. Only a truly nanocrystalline structure makes it possible to improve cardinally both the static and fatigue functional performances of $\mathrm{Ti}-\mathrm{Ni} \mathrm{SMA}$; the main obstacle being the technological capacity to form such a structure in large high-quality semi-products.

Acknowledgments The authors acknowledge financial support of National Sciences and Engineering Research Council of Canada, Fonds de Recherché Nature et Technologies du Québec and Ministry of Education and Science of Russian Federation.

\section{References}

1. Brailovski V, Prokoshkin SD, Terriault P, Trochu F (eds) (2003) Shape memory alloys: fundamentals, modeling and applications. ÉTS Publ, Montreal, p 851

2. Duerig TW, Melton KN, Stöckel D, Wayman CM (eds) (1990) Engineering aspects of shape memory alloys. ButterworthHeineman, London, p 499

3. Otsuka K, Wayman CM (eds) (1998) Shape memory materials. Cambridge University Press, Cambridge, p 284

4. Resnina N, Rubanik V (eds) (2015) Shape memory alloys: properties, technologies, opportunities. Trans Tech Publications, Zurich, p 640

5. Yahia L (ed) (2000) Shape memory implants. Springer-Verlag, Berlin, p 349

6. Yoneyama T, Miyazaki S (eds) (2009) Shape memory alloys for biomedical applications. Woodhead Publishing, Cambridge, p 337

7. Bernshtein ML, Khasenov BP, Khasyanov U (1987) Повторная реализация эффекта памяти формы в сплаве Ti-Ni (Repeated realization of shape memory effect in Ti-Ni alloy). Metal Sci Heat Treat 2:49-55 in Russian

8. Brailovski V, Khmelevskaya IY, Prokoshkin SD et al (2004) Foundations of heat and thermomechanical treatments and their effect on the structure and properties of titanium nickelide-based alloys. Phys Met Metallogr 97(Suppl. 1):S3-S55

9. Filip P, Mazanec K (1995) Influence of work hardening and heat treatment on the substructure and deformation behaviour of TiNi shape memory alloys. Scr Metall Mater 32(9):1375-1380

10. Khmelevskaya IY, Lagunova MI, Prokoshkin SD et al (1994) The reversible shape-memory effect in Ti-Ni-based alloys subjected to thermal and thermomechanical treatment. Phys Met Metallogr 78(1):57-60

11. Khmelevskaya IY, Prokoshkin SD, Dobatkin SV et al (2003) Structure and properties of severely deformed Ti-Ni-based shape memory alloys. J Phys IV 112:819-822

12. Khmelevskaya IY, Prokoshkin SD, Shipsha VG et al (2002) Thermomechanical strengthening of titanium nickelide and structure changes upon generation and forced isotermal relaxation of recovery stress. Phys Met Metallogr 93(2):189-195

13. Likhachev VA, Pomytkina SP, Shimansky SR (1989) Влияние термомеханической обработки на последовательность фазовых превращений в сплавах на основе $\mathrm{Ti}-\mathrm{Ni}$ (Influence of 
thermomechanical treatment on sequence of phase transformations in Ti-Ni-based alloys). Metal Sci Heat Treat 8:11-17 in Russian

14. Lin HC, Wu SK (1994) The tensile behavior of a cold-rolled and reverse-transformed equiatomic TiNi alloy. Acta Met Mater 42(5):1623-1630

15. Miyazaki S (1990) Thermal and stress cycling effects and fatigue properties of Ni-Ti alloys. In: Duerig TW, Melton KN, Stockel D, Wayman CM (eds) Engineering aspects of shape memory alloys. Butterworth-Heineman, London, pp 394-413

16. Miyazaki S, Imai T, Igo Y et al (1986) Effect of cyclic deformation on the pseudoelasticity characteristics of $\mathrm{Ti}-\mathrm{Ni}$ alloys. Metal Trans A 17(1):115-120

17. Miyazaki S, Ohmi Y, Otsuka K et al (1982) Characteristics of deformation and transformation pseudoelasticity in Ti-Ni alloys. J Phys 43(12):255-260

18. Miyazaki S, Otsuka K (1989) Development of shape memory alloys. ISIJ Int 29(5):353-377

19. Prokoshkin SD, Kaputkina LM, Bondareva SA et al (1991) Structure of hot-deformed austenite and properties of a Ti-Ni-Fe alloy after HTMT. Phys Met Metallogr 71(3):143-148

20. Prokoshkin SD, Khmelevskaya IY, Brailovski V et al (2004) Thermomechanical treatments and their influence on microstructure and stress-strain diagrams of Ni-Ti shape memory alloys. Can Metall Q 43(1):95-108

21. Treppmann D, Hornbogen E, Wurzel D (1995) The effect of combined recrystallization and precipitation on the functional and structural properties in TiNi alloys. J Phys III 5(12):569-574

22. Prokoshkin SD, Khmelevskaya IY, Brailovski V et al (2001) Structure and deformation diagrams of NiTi alloys subjected to a low-temperature thermomechanical treatment with postdeformation heating. Phys Met Metallogr 91(4):423-431

23. Valiev R (2002) Materials science: nanomaterial advantage. Nature 419:887-889

24. Valiev RZ, Aleksandrov IV (2000) Наноструктурные материалы, полученные с помошью интенсивной пластической деформации (Nanostructured materials obtained using severe plastic deformation), Moscow, p 272 in Russian

25. Fedorov VB, Kurdyumov VG, Khakimova DK et al (1983) Эффект измельчения зерна при пластической деформации никелида титана (Effect of grain refinement during the plastic deformation of titanium nickelide). Doklady Akad Nauk SSSR 269(4):885-888 in Russian

26. Tatyanin EV, Kurdyumov VG, Fedorov VB (1986) Obtaining of amorphous TiNi alloy by shear deformation under pressure. Phys Met Metallogr 62:133-137

27. Tatyanin EV, Kurdyumov VG (1990) Nucleation of the deformation induced amorphous phase at twin boundaries in TiNi alloy. Phys Stat Sol 121(2):455-459

28. Koike J, Parkin DM, Nastasi M (1990) Crystal-to-amorphous transformation of NiTi induced by cold rolling. J Mater Res 5(7):1414-1418

29. Khmelevskaya IY, Trubitsyna IB, Prokoshkin SD et al (2003) Thermomechanical treatment of Ti-Ni-based shape memory alloys using severe plastic deformation. Mater Sci Forum 426-432:2765-2770

30. Prokoshkin SD, Khmelevskaya IY, Dobatkin SV et al (2004) Structure evolution upon severe plastic deformation of TiNibased shape-memory alloys. Phys Met Metallogr 97(6):619-625

31. Prokoshkin SD, Khmelevskaya IY, Dobatkin SV et al (2005) Alloy composition, deformation temperature, pressure and postdeformation annealing effects in severely deformed Ti-Ni based shape memory alloys. Acta Mater 53(9):2703-2714

32. Pushin VG (2002) Structures, properties and application of nanostructured shape memory TiNi-based alloys. In Proceedings of International Conference "Nanomaterials by severe plastic deformation", NANO SPD2, Wiley-VCH Verlag, Vienna, pp 822-828

33. Zeldovich VI, Frolova YN, Pilyugin VP et al (2005) Formation of amorphous structure in titanium nickelide under plastic deformation. Phys Met Metallogr 99(4):425-434

34. Ewert JC, Bohm I, Peter R et al (1997) The role of the martensite transformation for the mechanical amorphisation of NiTi. Acta Mater 45(5):2197-2206

35. Nakayama H, Tsuchiya K, Umemoto M (2001) Crystal refinement and amorphization by cold rolling in TiNi shape memory alloys. Scr Mater 44(8-9):1781-1785

36. Prokoshkin SD, Brailovski V, Korotitskiy AV et al (2010) Specific features of the formation of the microstructure of titanium nickelide upon thermomechanical treatment including cold plastic deformation to degrees from moderate to severe. Phys Met Metallogr 110(3):289-303

37. Li ZC, Zhao XK, Zhang $\mathrm{H}$ et al (2003) Microstructure and superelasticity of severely deformed TiNi alloy. Mater Lett 57(5-6):1086-1090

38. Sergueeva AV, Song C, Valiev RZ et al (2003) Structure and properties of amorphous and nanocrystalline NiTi prepared by severe plastic deformation and annealing. Mater Sci Eng A 339(1-2):159-165

39. Waitz T, Kazykhanov V, Karnthaler HP (2004) Martensitic phase transformations in nanocrystalline NiTi studied by TEM. Acta Mater 52(1):137-147

40. Nakayama H, Tsuchiya K, Todaka Y et al (2003) Partial amorphization of B2 type shape memory alloys by cold rolling. J Metastable Nanocrystalline Mater 15-16:283-288

41. Stolyarov VV, Prokof'ev EA, Prokoshkin SD et al (2005) Structural features, mechanical properties, and the shape-memory effect in TiNi alloys subjected to equal-channel angular pressing. Phys Met Metallogr 100(6):608-618

42. Brailovski V, Prokoshkin SD, Khmelevskaya IY et al (2006) Structure and properties of the Ti-50.0 at.\% Ni alloy after strain hardening and nanocrystallizing thermomechanical processing. Mater Trans 47(3):795-804

43. Prokoshkin SD, Brailovski V, Inaekyan KE et al (2008) Structure and properties of severely cold-rolled and annealed $\mathrm{Ti}-\mathrm{Ni}$ shape memory alloys. Mater Sci Eng A 481-482:114-118

44. Prokoshkin SD, Brailovski V, Khmelevskaya IY et al (2005) Creation of substructure and nanostructure in thermomechanical treatment and control of functional properties of $\mathrm{Ti}-\mathrm{Ni}$ alloys with shape memory effect. Met Sci Heat Treat 47(5-6):182-187

45. Tsuchiya K, Hada Y, Koyano T et al (2009) Production of TiNi amorphous/nanocrystalline wires with high strength and elastic modulus by severe cold drawing. Scr Mater 60(9):749-752

46. Malard B, Pilch J, Sittner P et al (2011) In situ investigation of the fast microstructure evolution during electropulse treatment of cold drawn NiTi wires. Acta Mater 59(4):1542-1556

47. Inaekyan K, Brailovski V, Prokoshkin S et al (2009) Characterization of amorphous and nanocrystalline Ti-Ni-based shape memory alloys. J Alloy Compd 473(1-2):71-78

48. Peterlechner M, Bokeloh J, Wilde G et al (2010) Study of relaxation and crystallization kinetics of NiTi made amorphous by repeated cold rolling. Acta Mater 58(20):6637-6648

49. Inaekyan KE, Prokoshkin SD, Brailovski V et al (2006) Substructure and nanocrystalline structure effects in thermomechanically treated Ti-Ni alloys. Mater Sci Forum 503-504:597-602

50. Inaekyan K, Brailovski V, Korotitskiy A, et al. (2009) Microhardness of binary near-equiatomic Ti-Ni alloys after severe cold rolling and post-deformation annealing, in European Symposia on Martensitic Transformation (ESOMAT 2009), Czech Republic. doi: 10.1051/esomat/200905011

51. Brailovski V, Prokoshkin SD, Khmelevskaya IY et al (2006) Interrelations between the properties and structure of 
thermomechanically-treated equiatomic Ti-Ni alloy. Mater Sci Eng A 438-440:597-601

52. Zhao M, Li JC, Jiang Q (2003) Hall-Petch relationship in nanometer size range. J Alloy Compd 361:160-164

53. Hyoung Seop K (1998) A composite model for mechanical properties of nanocrystalline materials. Scr Mater 39(8): $1057-1061$

54. Qing X, Xingming G (2006) The scale effect on the yield strength of nanocrystalline materials. Int J Solids Struct 43(25-26): 7793-7799

55. Prokoshkin S, Brailovski V, Inaekyan K et al. (2007) Severely cold-rolled and annealed Ti-Ni shape memory alloys: structure, transformations and functional properties. In: Proceedings of International Symposium "Bulk Nanostructured Materials, BNM 2007”, Ufa, pp 282-283

56. Demers V, Brailovski V, Prokoshkin SD et al (2009) Optimization of the cold rolling processing for continuous manufacturing of nanostructured Ti-Ni shape memory alloys. J Mater Process Technol 209(6):3096-3105

57. Hornbogen E (2004) Review thermo-mechanical fatigue of shape memory alloys. J Mater Sci 39(2):385-399

58. Brailovski V, Prokoshkin S, Inaekyan K et al (2011) Functional properties of nanocrystalline, submicrocrystalline and polygonized Ti-Ni alloys processed by cold rolling and post-deformation annealing. J Alloy Compd 509(5):2066-2075

59. Kreitcberg A, Brailovski V, Prokoshkin S et al (2013) Microstructure and functional fatigue of nanostructured Ti50.26 at.\% Ni alloy after thermomechanical treatment with warm rolling and intermediate annealing. Mater Sci Eng A 562: $118-127$

60. Demers V, Brailovski V, Prokoshkin SD et al (2009) Thermomechanical fatigue of nanostructured Ti-Ni shape memory alloys. Mater Sci Eng A 513-514((C)):185-196

61. Kreitcberg A, Brailovski V, Prokoshkin PD (2014) Influence of thermomechanical treatment on structure and crack propagation in nanostructured Ti-50.26 at.\% Ni alloy. Metallogr Microstruct Anal 3(1):46-57

62. Kreitcberg AY, Prokoshkin SD, Brailovski V et al (2014) Role of the structure and texture in the realization of the recovery strain resource of the nanostructured Ti-50.26 at.\% Ni alloy. Phys Met Metallogr 115(9):926-947

63. Facchinello Y, Brailovski V, Prokoshkin SD et al (2012) Manufacturing of nanostructured $\mathrm{Ti}-\mathrm{Ni}$ shape memory alloys by means of cold/warm rolling and annealing thermal treatment. J Mater Process Technol 212(11):2294-2304

64. Kreitcberg A, Brailovski V, Prokoshkin S et al (2015) Effect of the grain/subgrain size on the strain-rate sensitivity and deformability of Ti-50.0 at.\% Ni alloy. Mater Sci Eng A 622:21-29

65. Kreitcberg A, Prokoshkin S, Brailovski V et al. (2014) Influence of the strain rate and deformation temperature on the deformability of Ti-Ni SMAs: A preliminary study, 6th International Conference on Nanomaterials by Severe Plastic Deformation, NanoSPD 2014, IOP Conference Series: Materials Science and Engineering. doi: 10.1088/1757-899X/63/1/012109 